\section{iglesia en gandía}

$148 \cdot 76$ emplazamiento: Grao de Gandía aก̃o: 1961

arquitecto: GONZALO ECHEGARAY ingeniero: JAIME NADAL

constructor: Sicop

\title{
Empleczen miemto
}

El solar destinado para la construcción del nuevo centro está situado en un saliente de tierra, frente al Puerto, con forma sensiblemente triangular, y se halla limitado por su lado oeste con la carretera, quedando los otros dos lados en forma de cuña o espolón que penetra en el mar.

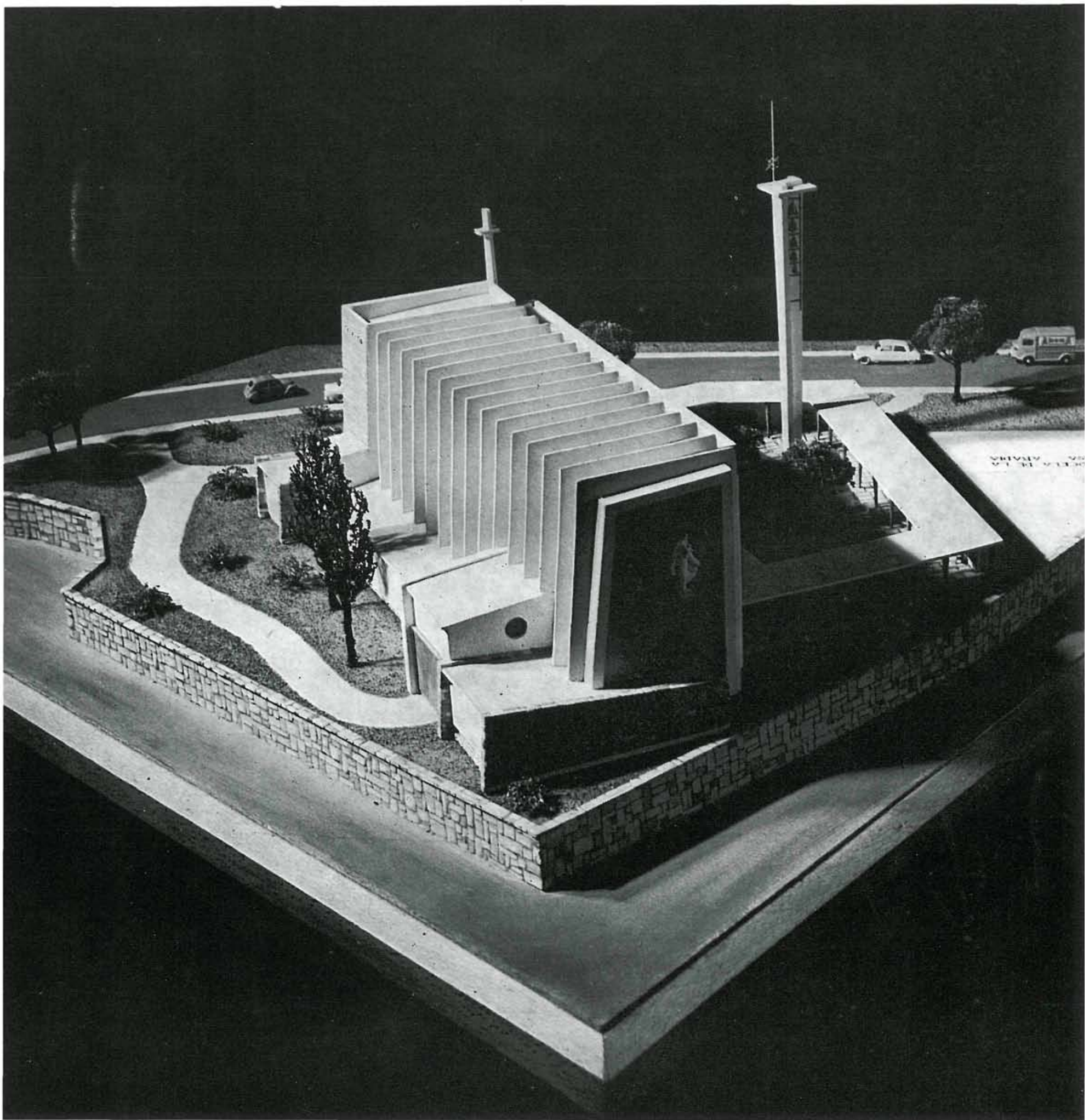


La superficie del solar es bastante horizontal, pero, por encontrarse en una cota por debajo del nivel de la carretera, se proyec tó el terraplenado de toda de toda la zona que rodea el nuevo templo, con el fin de que el nivel de la nave princi. pal y accesos se encuentre por encima del de la ca. rretera y tenga la debida altura en relación con la nobleza y fin a que está destinada la construcción.

\section{Esक 4.}

\section{dele wollumemes}

La edificación se ha pro yectado con una altura en consonancia con la super ficie de la nave principal, preocupándose de que, en todo mom e n t o y desde cualquier ángulo, destaque esta nave principal elemento básico de composición. Para contrastar y valorizar este volumen principal, el claustro es de desarrollo horizontal y sirve de enlace con la Casa Abadía, edificio sencillo que, por alojar el despacho parroquial, era necesario incluir.

\section{Comm possición món}

A través del porche, que corre ante el alzado principal, y a su derecha, están situadas las puertas de acceso a un vestíbulo, cortavientos, desde el que se pasa a la nave de la Iglesia. En los dos juegos de puertas del vestíbulo se ha marcado, de un modo cla. ro, la doble circulación de con este vestíbulo, pero separado por una cancela que impide el libre paso, se sitúa el baptisterio, de modo que su recinto que de fuera de la nave principal.











La nave se ha trazado en planta de forma trapezoidal, con el deseo de forzar la perspectiva en fuga de líneas que convergen en el presbiterio. A la derecha aparecen cinco capillas laterales, y una, de mayor tamaño, destinada a albergar el Paso.

La iluminación de estas capillas es indirecta, apareciendo, en su frente sur, una serie de huecos de colores como expresión y símbolo de la tradicional y representativa vidriera religiosa.

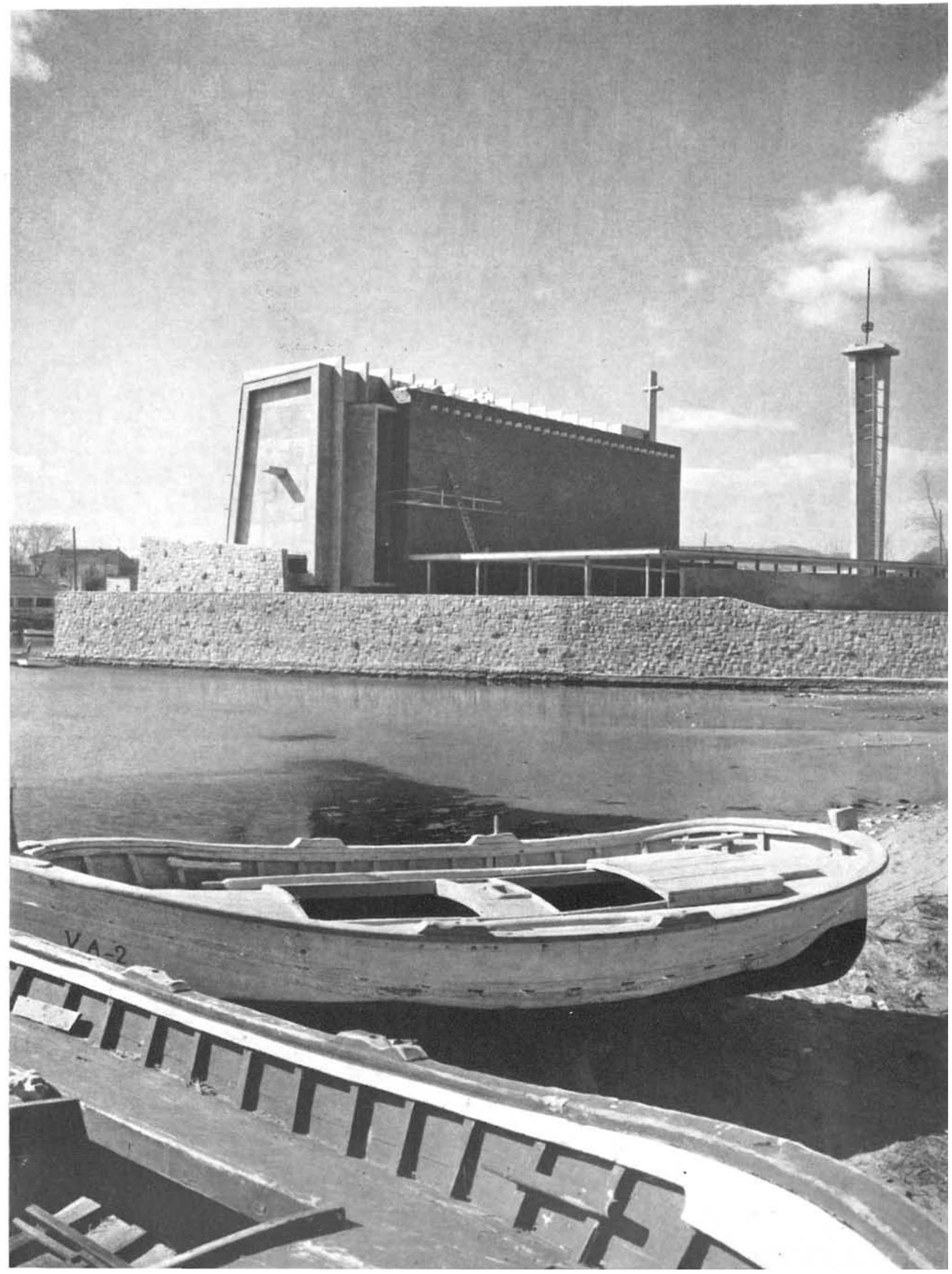




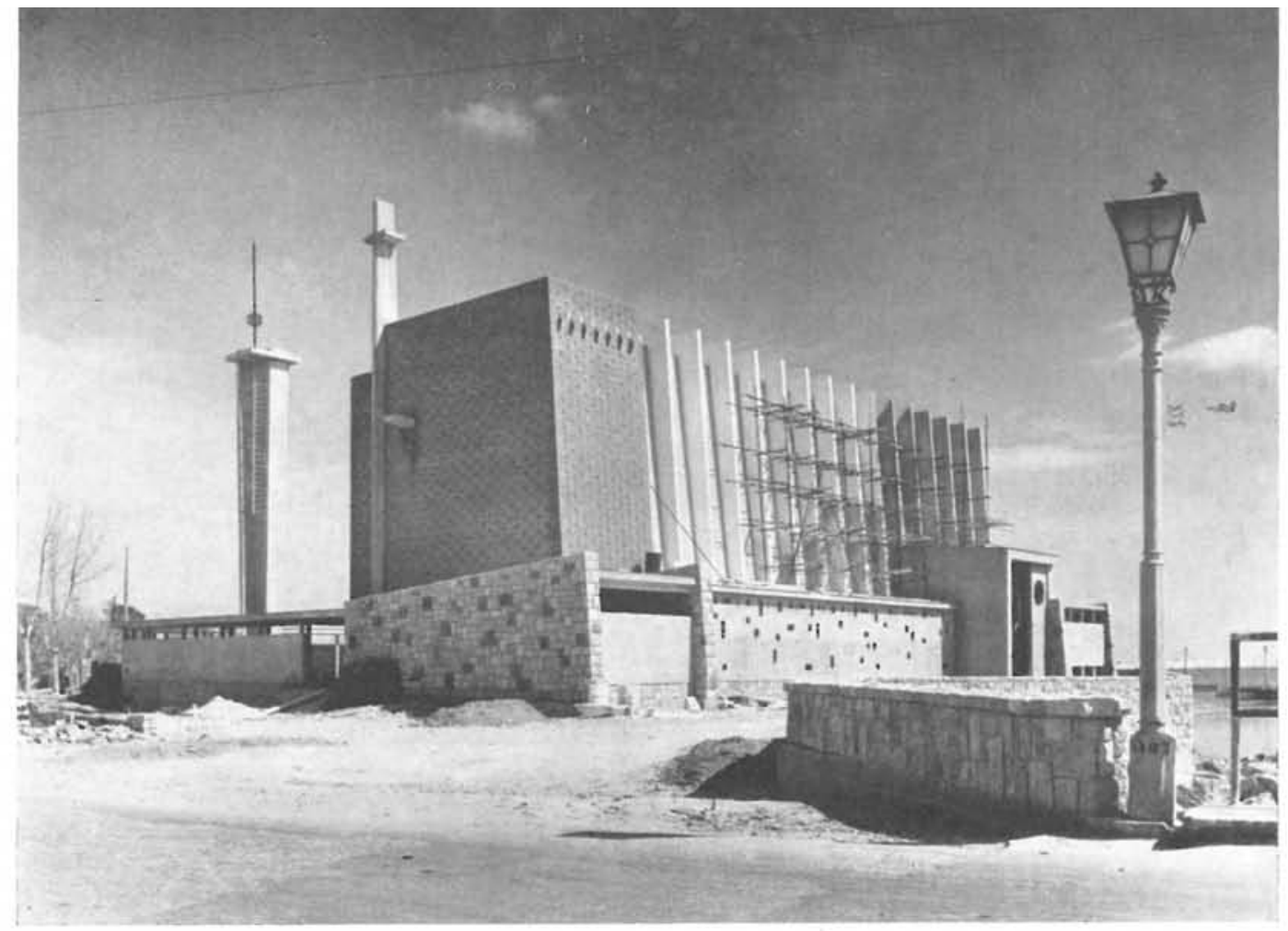

La separación de estas capillas se efectúa de un modo parcial, con unos muretes bajos de piedra. Esta solución permite que la visibilidad del Altar sea completa, pudiendo seguir la Santa Misa desde dentro de las capillas, lo que, en caso de necesidad, aumenta grandemente la superficie útil del templo.

A la izquierda, y cubriendo casi toda la zona baja de este frente norte, aparece un hueco corrido, cerrado con puertas correderas transparentes, que incorpora el claustro, tranquilo y silencioso, a la nave. Esta solución, que estéticamente puede ser de una gran belleza, se ha estudiado, principalmente, desde un punto de vista funcional, con el fin de conseguir que en el verano, época en la que el incremento de la población producido por la colonia veraniega tiene una gran im. portancia, al abrir las puertas correderas, la nave y el claustro quedan totalmente enlazados, aumentando casi al doble la capacidad de la zona desde la que se puede seguir correctamente la Santa Misa.

La iluminación principal de la nave se efectúa por un ventanal corrido orientado al norte y que marca la independencia existente entre los dos paños de estructura que cierran la nave.

En el frente de la nave, y encuadrado con una embocadura asimétrica, aparece el presbiterio, sobre el que se alza el Altar exento, coronado por una gran Cruz. Se ha forzado la sencillez de la composición haciendo que destaquen sus únicos elementos con el valor y la fuerza que por sí mismo tienen. Se ilumina este frente del Altar con un ventanal lateral oculto, que cerrado con vidrios de colores acentúa la composición asimétrica con que está concebido el proyecto. Al lado izquierdo de la embocadura se sitúa el ambón con tornavoz, formado por un murete de piedra.

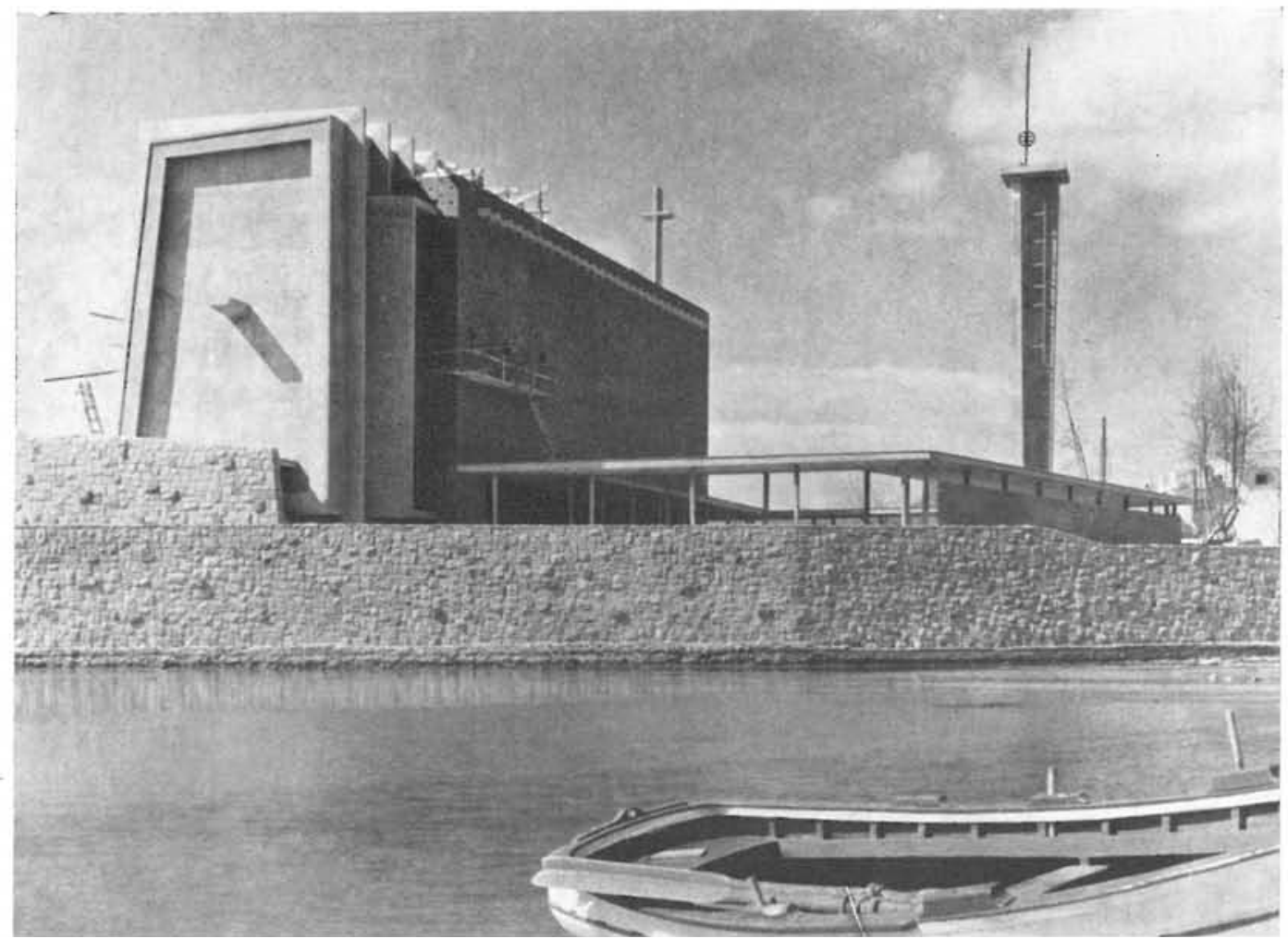




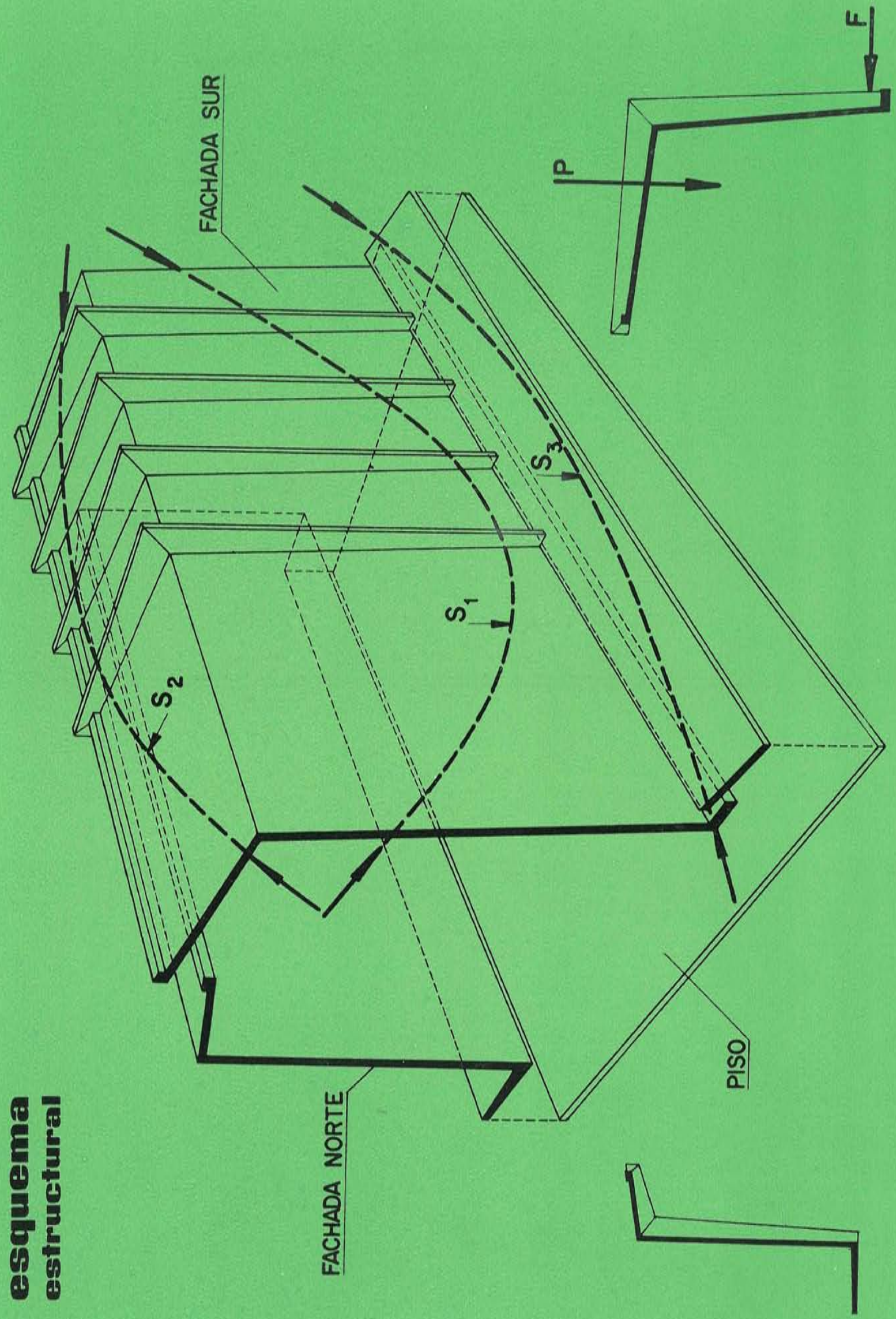



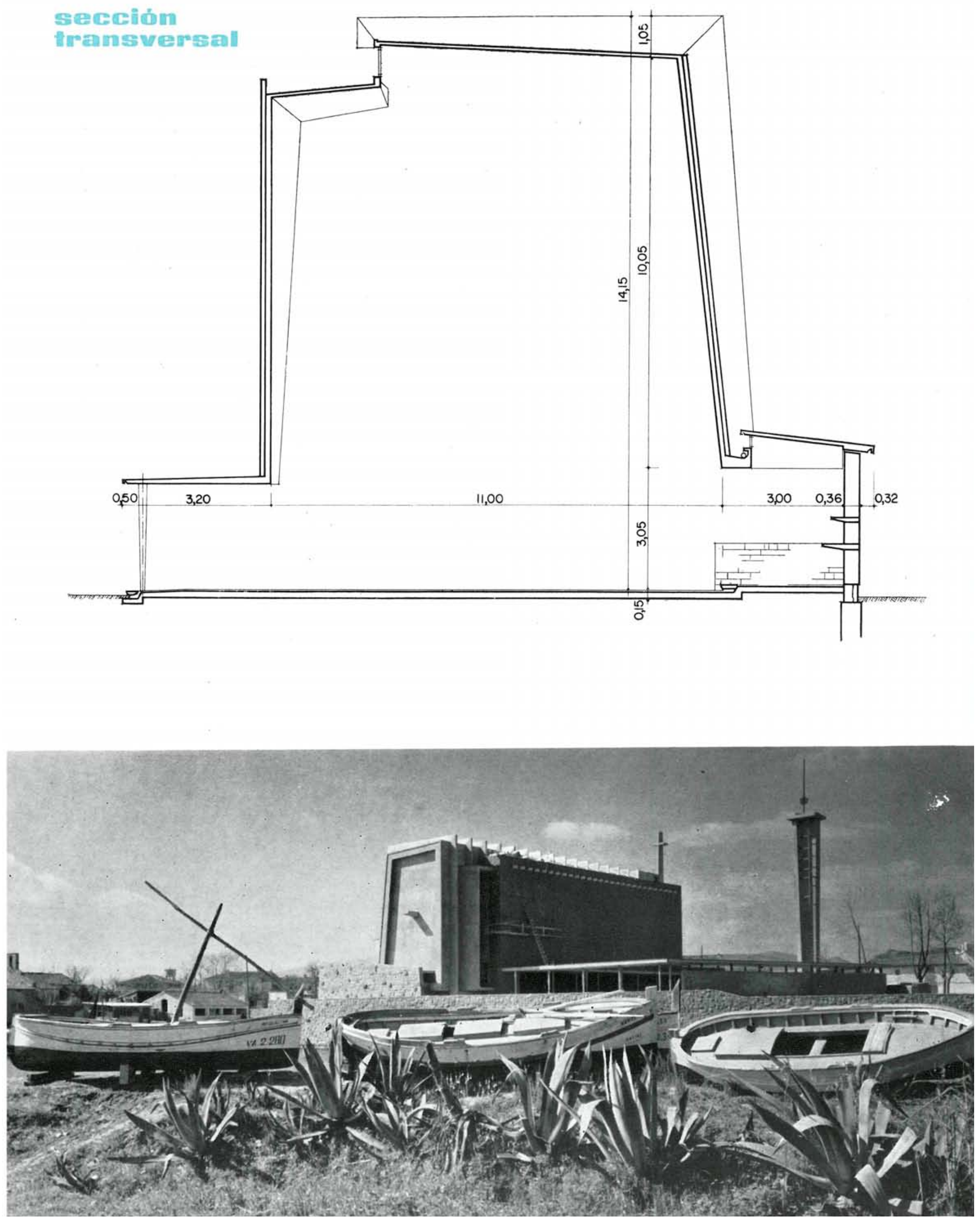

(C) Consejo Superior de Investigaciones Científicas Licencia Creative Commons 3.0 España (by-nc) 


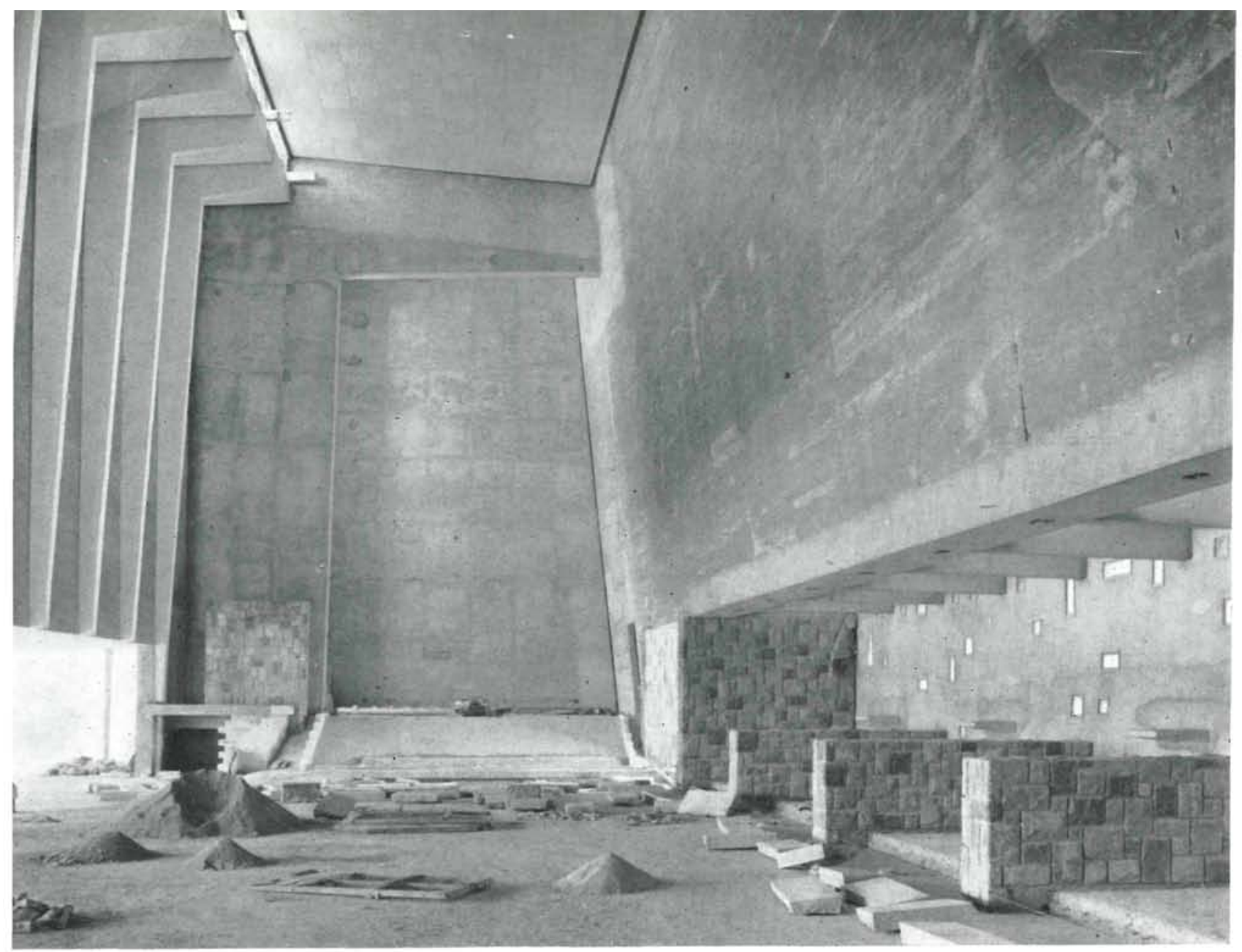

\section{Estreuctoren}

La estructura está formada por una doble fila de nervios quebrados que en el paramento norte aparecen al interior de la nave y en el sur salen al exterior y son los elementos rigidizadores de y son los elementos rigidizadores de apoyan en los piñones de fachada prin cipal y fondo del Altar. Independiente de sus altos valores estéticos, a esta forma en deseo de que la cobertura de la nave, esto es, los para mentos que cierran y delimitan el tem plo, aparezcan aéreos y ligeros como si el material utilizado, pesado y recio, se transformase en función del alto destino para el que había sido elegido, ad. quiriendo valores de ingravidad y liguiriena.

La viga-muro correspondiente a la fa chada norte se halla unida inferiormente a la cubierta del claustro, de tal forma que queda constituída una viga de sección en $Z$. La viga-muro corres pondiente a la fachada sur tiene una pondiente a la fachada
sección en $L$ invertida.

Una viga de sección en $\mathrm{L}$, de pared delgada, se encuentra sometida a torsiones siempre que la resultante de las fuerzas exteriores no pasa por el centro de esfuerzos cortantes, que, en este tro de esfuerzos cortantes, que, en este caso, es el vértice de la L. Como la re sultante, $\mathrm{P}$, de los pesos muertos no pasa por dicho punto, se originan esuerzos de torsión, imposibles de soportar con la sección en pared delgada abierta.

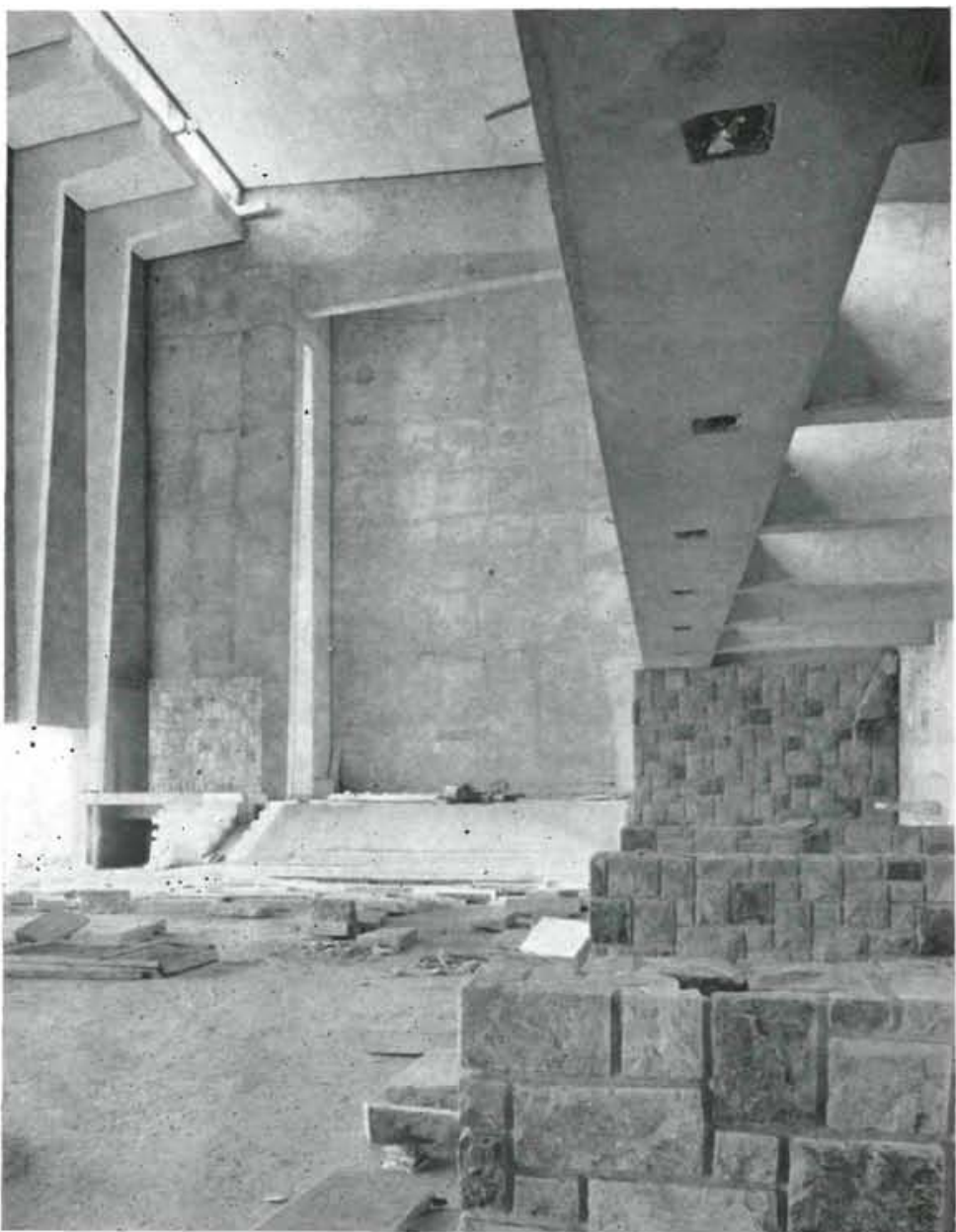




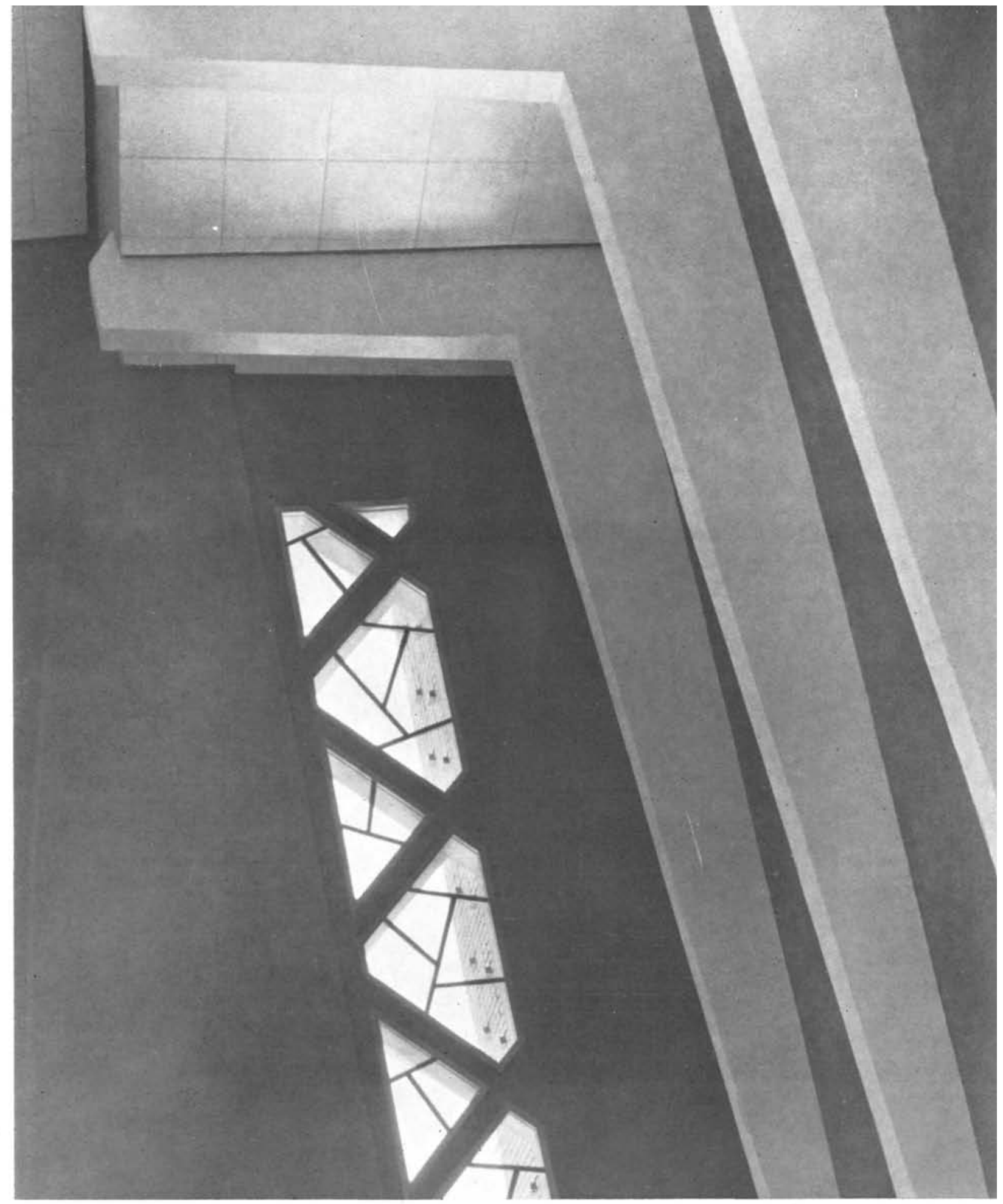

Para eliminar estas torsiones se introducen las fuerzas, F, que originan momentos torsores respecto al centro de esfuerzos cortantes que anulan los producidos por P. Estas fuerzas F se originan por medio del sistema de pretensado, S, situado en la cubierta de las capillas laterales.

La viga en L correspondiente a la fachada sur está, por tanto, sometida a dos sistemas de fuerzas, P y F, que producen flexiones en planos vertical y horizontal, respectivamente.

Estas flexiones están absorbidas por los sistemas de pretensado, $\mathrm{S}_{1}$ y $\mathrm{S}_{2}$, lográndose con esto eliminar las tensiones cortantes de torsión, y la pared y la cubierta quedan libres de tracciones, con lo que se mejora nota blemente su impermeabilidad.

La viga en $\mathrm{Z}$ correspondiente a la fachada norte lleva unos sistemas de pretensado análogos a los descritos.

Ambas vigas apoyan sobre las estructuras de las fachadas este y oeste, siendo una de ellas móvil para poder admitir las dilataciones o contracciones de aquéllas. 